\title{
Radar-radiometer retrievals of cloud number concentration and dispersion parameter in nondrizzling marine stratocumulus
}

\author{
J. Rémillard ${ }^{1, *}$, P. Kollias ${ }^{1}$, and W. Szyrmer ${ }^{1}$ \\ ${ }^{1}$ Department of Atmospheric and Oceanic Sciences, McGill University, Montreal, QC, Canada \\ * currently at: Department of Applied Physics and Applied Mathematics, Columbia University, New York, USA
}

Correspondence to: J. Rémillard (jasmine.remillard@mail.mcgill.ca)

Received: 26 September 2012 - Published in Atmos. Meas. Tech. Discuss.: 16 October 2012

Revised: 15 June 2013 - Accepted: 18 June 2013 - Published: 30 July 2013

\begin{abstract}
The retrieval of cloud microphysical properties from remote sensors is challenging. In the past, ground-based radar-radiometer measurements have been successfully used to retrieve the liquid water content profile in nondrizzling clouds but offer little constraint in retrieving other moments of the cloud particle size distribution (PSD). Here, a microphysical condensational model under steady-state supersaturation conditions is utilized to provide additional constraints to the well-established radar-radiometer retrieval techniques. The coupling of the model with the observations allows the retrieval of the three parameters of a lognormal PSD, with two of them being height dependent. Two periods of stratocumulus from the Azores are used to evaluate the novel technique. The results appear reasonable in two nondrizzling periods: continental-like number concentrations are retrieved, in agreement with the drizzle-free cloud conditions. The cloud optical depth derived from the retrieved distributions compares well in magnitude and variability with the one derived independently from a narrow field of view zenith radiometer. Uncertainties coming from the measurements are propagated to the retrieved quantities to estimate their errors. In general, errors smaller than $20 \%$ should be attainable for most parameters, demonstrating the added value of the new technique.
\end{abstract}

\section{Introduction}

Extensive sheets of stratus and stratocumulus clouds lie above the eastern boundary current upwelling regions over the world's oceans (Klein and Hartmann, 1993). Marine stratocumulus clouds play a critical role in the boundary layer dynamics and are a key component in the earth's radiation budget (Randall et al., 1984; Ramanathan et al., 1989; Bony and Dufresne, 2005). However, appreciable complexity and challenges are found on small space and time scales, including the cloud scale that is on the order of tens of meters and a few minutes or less (Stevens and Feingold, 2009). If all other parameters are fixed, an increased aerosol concentration may reduce cloud droplet sizes, and therefore increase cloud optical thickness (the Twomey effect, Twomey, 1977). In turn, reduced cloud droplet sizes can lead to precipitation suppression and increase the cloud lifetime (the Albrecht effect, Albrecht, 1989). However, recent modelling studies have suggested that elevated cloud condensation nuclei concentrations can also affect entrainment of free tropospheric air in the marine boundary layer (e.g., Ackerman et al., 2004), thus leading to important feedbacks that include both key processes.

Providing observational constraints for these processes at the cloud-scale requires coordinated synergistic, multiplatform measurements. In situ aircraft-based observations provide direct measurements of cloud thermodynamical and microphysical properties, but are temporally and spatially limited. Ground-based supersites (e.g., Ackerman and Stokes, 2003) offer the advantage of continuous, multiinstrument observations. Relating the ground-based measurements to the variables of interest requires the use of physical or statistical retrieval techniques (e.g., Turner et al., 2007a). Here, we are concerned with the retrieval of microphysical properties of nondrizzling stratocumulus clouds where condensation in an updraft and evaporation in downdrafts due to cloud-top mixing are the key processes that determine the profile of cloud microphysical properties. 
Several previous studies have focused on the retrieval of microphysical processes in marine stratocumulus (Frisch et al., 1995, 1998, 2002; Fox and Illingworth, 1997; Kato et al., 2001; Turner et al., 2007a). Frisch et al. (1998) first introduced the combination of radar-radiometer measurements to retrieve the in-cloud profile of liquid water content. Drizzle occurrence limits the applicability of the technique, and either the use of a radar reflectivity threshold (e.g., Liu et al., 2008) or the absence of radar echoes below the cloud base is used to remove drizzling clouds. In the absence of radiometer measurements, a variety of regressionbased power law relations between the radar reflectivity factor and the liquid water content have been proposed (Atlas, 1954; Sauvageot and Omar, 1987; Sassen and Liao, 1996; Fox and Illingworth, 1997; Wang and Geerts, 2003; Kogan et al., 2007). The review paper of Turner et al. (2007a) shows the large differences among the state-of-the-art liquid water content retrievals in nonprecipitating thin liquid clouds. Cloud optical depth measurements have also been used to constrain the microphysical retrievals in stratocumulus clouds (Dong et al., 1997; Mace and Sassen, 2000; Kim et al., 2008; McComiskey et al., 2009). More recently, Martucci and O'Dowd (2011) developed a new technique combining radar and lidar profiles.

A new retrieval method is developed here, building on the previous retrieval technique introduced by Frisch et al. (1995, 1998) that used the combination of radar and radiometer measurements. Assuming that condensation and evaporation are the only processes controlling the evolution of the cloud particle size distribution (PSD), the vertical gradient of the attenuation-corrected radar reflectivity is used to derive the dispersion parameter ( $\sigma$, assumed constant in the column) and the number concentration $\left(N_{\text {cld }}\right.$, allowed to vary vertically around the derived column-averaged value). The observed mean Doppler velocity is used as a proxy for the vertical air motion, and it is used to estimate the supersaturation in the cloud.

This paper first briefly describes the typical instruments available. The novel approach is then described and illustrated by a couple of examples from the Azores. Finally, the results are compared to another instrument's measurements, to assess the feasibility of this technique.

\section{Observations}

The study utilizes marine stratocumulus observations collected during the recent deployment of the US Department of Energy Atmospheric Radiation Measurement (ARM) Mobile Facility (AMF) on Graciosa Island, Azores, in the context of the Clouds, Aerosol and Precipitation in the Marine Boundary Layer (CAP-MBL) field campaign. CAPMBL took place from April 2009 to December 2010 in the Azores, to collect data on the physical and radiative properties of low-level clouds. The analysis is limited to low-level
Table 1. Cloud properties measured or derived from ARM observations in the Azores.

\begin{tabular}{lll}
\hline Measured quantity & Variable & Instrument \\
\hline Radar reflectivity & $Z\left(\mathrm{~mm}^{6} \mathrm{~m}^{-3}\right)$ & WACR \\
Cloud top height & $h_{\mathrm{TOP}}(\mathrm{m})$ & WACR \\
Cloud base height & $h_{\mathrm{BASE}}(\mathrm{m})$ & Ceilometer \\
Cloud vertical air motion & $w_{\text {air }}\left(\mathrm{m} \mathrm{s}^{-1}\right)$ & WACR \\
Cloud liquid water path & $\mathrm{LWP}\left(\mathrm{g} \mathrm{m}^{-2}\right)$ & MWR \\
Cloud optical depth & $\tau_{\mathrm{NFOV}}$ & NFOV \\
\hline
\end{tabular}

nonprecipitating marine stratocumulus clouds in the absence of other clouds, especially those containing liquid particles (e.g., cumulus).

Measurements from the W-band ARM Cloud Radar (WACR; Mead and Widener, 2005), two 2-channel microwave radiometers (MWR; Turner et al., 2007b), the ceilometer (Münkel et al., 2007), and the 2-channel Narrow Field of View Zenith Radiometer (NFOV; Chiu et al., 2006) are used in this study (Table 1). Time-series measurements of column-integrated amounts of water vapor (the precipitable water vapor, PWV) and liquid water (the liquid water path, LWP) are provided from the MWRs. The uncertainty in the MWR-retrieved LWP is typically better than $20 \mathrm{~g} \mathrm{~m}^{-2}$, depending on the retrieval method (Turner et al., 2007a). Cloud optical depth $\tau$ measurements are available from the NFOV at $1 \mathrm{~s}$ resolution (Chiu et al., 2006). Subsequently, the cloudtop effective radius $r_{\mathrm{e}, \mathrm{CT}}$ can be estimated from $\tau_{\mathrm{NFOV}}$ and LWP (e.g., Wood and Hartmann, 2006) using the expression

$r_{\mathrm{e}, \mathrm{CT}}=9 \mathrm{LWP} /\left(5 \rho_{\mathrm{w}} \tau_{\mathrm{NFOV}}\right)$.

This relationship assumes that liquid water content increases linearly with height, while the droplets concentration remains about constant. The ceilometer provides estimates of the cloud base height, and it is used in conjunction with the WACR data to ensure that the selected period contains no significant drizzle (i.e., WACR echoes below the cloud base).

The WACR provides information on the vertical structure of the marine stratocumulus clouds as depicted by the radar reflectivity $(Z)$ and mean Doppler velocity $\left(V_{\mathrm{d}}\right)$ measurements, obtained at temporal and vertical resolutions of, respectively, near $2 \mathrm{~s}$ and $43 \mathrm{~m}$. Although the time resolution is coarser for the ceilometer and MWR than the radar, their measurements used here (namely the ceilometer cloud base and the LWP and PWV from the MWR) are derived from a time integration over the sampling interval, and they should vary smoothly for stratocumulus situations. Consequently, it is assumed that these measurements can be equally applied to their full sampling interval, allowing us to bring their temporal resolution to the radar-native one. This is an advantage, as the retrieval method described in the next section relies heavily on $Z$ and its height derivative.

Based on work done by Meneghini (1978) and Matrosov et al. (2004), the WACR reflectivity profiles are corrected 
for attenuation from water vapor and liquid water, using the PWV and LWP measurements provided by the MWR. Following Eq. (9) of Matrosov et al. (2004), the vapor is distributed exponentially in the column, according to the surface pressure and temperature obtained from the soundings. For the liquid water correction, Eq. (10) of Meneghini (1978) is used, making sure the results at cloud top coincide with those obtained from Eq. (12) of Matrosov et al. (2004). These methods provide a first-order estimate of the corrections for $Z$, with further fine-tuning having a much smaller impact that will be included in the errors instead. Information on temperature and pressure is obtained from the Balloon-Borne Sounding System (BBSS), which provides vertical profiles of both the thermodynamic state of the atmosphere, and the wind speed and direction. Overall, water vapor and liquid water from a typical stratocumulus cloud in the Azores can produce a total two-way attenuation of 1-2 $\mathrm{dB}$ each, but oxygen attenuation remains negligible (as estimated from Eq. 10 of Matrosov et al., 2004).

\section{Retrieval method}

Typically, an analytical form is chosen to represent the cloud PSD such that its moments depend only on three parameters: a characteristic size, a dispersion parameter, and a concentration parameter. One of the widely used forms is the lognormal PSD:

$n(r)=\frac{N_{\mathrm{cld}}}{\sqrt{2 \pi} \sigma r} \exp \left(\frac{-\left(\ln r-\ln r_{0}\right)^{2}}{2 \sigma^{2}}\right)$,

where $r$ is the droplet's radius, $N_{\text {cld }}$ the number concentration, $r_{0}$ the median radius, and $\sigma$ the lognormal width (a measure of the PSD dispersion). Such a PSD form yields the following $k$ th moment (see Frisch et al., 1995):

$$
\int_{0}^{\infty} r^{k} n(r) \mathrm{d} r=N_{\mathrm{cld}} r_{0}^{k} \exp \left(\frac{k^{2}}{2} \sigma^{2}\right) .
$$

The bulk quantities of the distribution that represent physical quantities of interest are directly related to the moments of the cloud PSD. For instance, the liquid water content (LWC) relates to the third moment of the PSD, resulting in the following:

$Q_{\mathrm{c}}=\frac{4 \pi \rho_{\mathrm{w}}}{3} \int_{0}^{\infty} r^{3} n(r) \mathrm{d} r=\frac{4 \pi \rho_{\mathrm{w}}}{3} N_{\mathrm{cld}} r_{0}^{3} \exp \left(\frac{9}{2} \sigma^{2}\right)$,

where $\rho_{\mathrm{w}}$ is the water density. The radar reflectivity factor $(Z)$ is proportional to the backscattering cross-section of the droplets, which in turn relates to the sixth moment of the PSD since droplets are much smaller than the radar wavelength.
Therefore, $Z$ can be written as

$Z=2^{6} \int_{0}^{\infty} r^{6} n(r) \mathrm{d} r=2^{6} N_{\mathrm{cld}} r_{0}^{6} \exp \left(18 \sigma^{2}\right)$.

Combining Eqs. (4) and (5), the dependence on one of the PSD parameters can be removed:

$Q_{\mathrm{c}}=\frac{\pi \rho_{\mathrm{w}}}{6} \frac{\sqrt{N_{\mathrm{cld}} Z}}{\exp \left(\frac{9}{2} \sigma^{2}\right)}$.

The application of Eq. (6) requires that either drizzle particles are absent or their presence does not affect the radar reflectivity profile. Alternatively, a separation of the measured $Z$ values into their cloud and drizzle parts would be sufficient.

Analysis of a large database of in situ measurements taken in marine stratocumulus clouds suggests that the cloud concentration number and dispersion parameter are approximately constant with height (e.g., Miles et al., 2000) ${ }^{1}$. Based on these observations, most aforementioned retrievals algorithms also treat these two variables as invariant with height (e.g., Frisch et al., 1998). However, in situ measurements are typically taken from horizontal flight legs at three levels in the clouds, with one near the base and one near the top. This creates a vertical resolution that appears rather coarse to conclude an invariance with height. Here, we only assume that $\sigma$ is constant with height, and its value is estimated from the calculated column-averaged number concentration. To find that last quantity, we require that the variations of $N_{\text {cld }}$ around its column average remain small (see below for details). This requirement should make the height variations in the retrieved profiles similar to those observed in situ.

Integrating Eq. (6) throughout the cloud layer provides an equation for the LWP:

LWP $=\frac{\pi \rho_{\mathrm{w}}}{6} \frac{\left\langle N_{\mathrm{cld}}^{1 / 2}\right\rangle}{\exp \left(\frac{9}{2} \sigma^{2}\right)} \int_{\text {base }}^{\text {top }} \sqrt{Z(z)} \mathrm{d} z$,

where the angled brackets represent a column averaging, weighted by the square-root of reflectivity: $\left\langle N_{\text {cld }}^{1 / 2}\right\rangle=$ $\int_{\text {base }}^{\text {top }} \sqrt{N_{\text {cld }}(z)} \sqrt{Z(z)} \mathrm{d} z / \int_{\text {base }}^{\text {top }} \sqrt{Z(z)} \mathrm{d} z$. Notice that the weighting function choice is simply driven by the need to keep only observable quantities in the integral. Rearranging the terms in Eq. (7) allows the isolation of a column-averaged

\footnotetext{
${ }^{1}$ Although Miles et al. (2000) worked with various $\sigma$ s, their discussion revolves mainly around one: the standard deviation about the mean diameter (with subscript $v, o b s$ ). This quantity is typically observed to increase with the mean diameter, while their ratio (named the spectral dispersion) is about constant with height (see their Fig. 5 and linked discussion). Their Eqs. (7b) and (7c) show this spectral dispersion is directly related to the lognormal width we use.
} 
$N_{\text {cld }}$, albeit normalized by a function of the PSD dispersion, which we will refer to as $N_{\text {norm }}$ :

$N_{\text {norm }}^{1 / 2} \equiv \frac{\left\langle N_{\text {cld }}^{1 / 2}\right\rangle}{\exp \left(\frac{9}{2} \sigma^{2}\right)}=\frac{6 \mathrm{LWP}}{\pi \rho_{\mathrm{w}} \int_{\text {base }}^{\text {top }} \sqrt{Z(z)} \mathrm{d} z}$.

With LWP measurements available from the MWR, this normalized number concentration can be computed, and is thus considered an observable. The derivation of the last relation is the same as in Frisch et al. (1995), but with the column-constant $N_{\text {cld }}$ replaced with the column-averaged value $\left\langle N_{\text {cld }}^{1 / 2}\right\rangle$.

In order to estimate the $N_{\text {cld }}$ at a given height from the calculated $N_{\text {norm }}^{1 / 2}$ in Eq. (8), we use the profile of vertical gradient of reflectivity. The vertical changes of reflectivity have to reflect the evolution of PSD via active microphysical processes. In the absence of precipitation processes, the cloud droplets are assumed to grow only by condensation (and evaporation) as they follow the air motions. As such, the changes in reflectivity values are simply linked to the condensation/evaporation process, and the particle size growth rate is described by the following equation (e.g., Rogers and Yau, 1989):

$\frac{\mathrm{d} r}{\mathrm{~d} t}=\frac{S-\frac{a}{r}+\frac{b}{r^{3}}}{r\left[F_{\mathrm{k}}+F_{\mathrm{D}}\right]}$

where $t$ is the time, $S$ is the degree of saturation, $a$ and $b$ are constants depending on the curvature and solute of the droplet, and $F_{\mathrm{k}}$ and $F_{\mathrm{D}}$ are atmospheric factors accounting for the thermal and diffusion effects, respectively (see Appendix Table A1 for their full expressions). Once initial droplets are formed, the curvature and solute terms can usually be neglected, leaving a simple form for the droplet's growth (and evaporation if $S<0$ ). The time coordinate here relates to the height coordinate $(z)$ through the vertical air motion $\left(w_{\text {air }}\right)$, as cloud droplets sizes remain small enough to produce only negligible fall speeds. Equation (9) thus becomes

$\frac{\mathrm{d} r}{\mathrm{~d} z}=\frac{S}{r w_{\mathrm{air}}\left[F_{\mathrm{k}}+F_{\mathrm{D}}\right]}$.

On the other hand, the radar reflectivity factor is given by Eq. (5). In its most common units (dBZ), the reflectivity changes with height can then be written as

$$
\frac{\mathrm{d}(\mathrm{dBZ})}{\mathrm{d} z}=\frac{4.34}{Z} \frac{\mathrm{d} Z}{\mathrm{~d} z}=\frac{4.34}{\int_{0}^{\infty} r^{6} n(r) \mathrm{d} r} \int_{0}^{\infty} 6 r^{5} \frac{\mathrm{d} r}{\mathrm{~d} z} n(r) \mathrm{d} r .
$$

Using Eq. (10) for the change of radius with height, we get

$$
\begin{aligned}
\frac{\mathrm{d}(\mathrm{dBZ})}{\mathrm{d} z} & =\frac{26.04 S}{w_{\text {air }}\left[F_{\mathrm{k}}+F_{\mathrm{D}}\right]} \frac{\int_{0}^{\infty} r^{4} n(r) \mathrm{d} r}{\int_{0}^{\infty} r^{6} n(r) \mathrm{d} r} \\
& =\frac{26.04 S}{w_{\text {air }}\left[F_{\mathrm{k}}+F_{\mathrm{D}}\right]} \frac{1}{r_{0}^{2} \exp \left(10 \sigma^{2}\right)},
\end{aligned}
$$

where a lognormal PSD has been used to estimate the integrals (see Eq. 3).

Finally, it is assumed that steady-state conditions are reached and maintained inside the cloud (excluding the edges). Therefore, a steady-state supersaturation will be used, as derived by Korolev and Mazin (2003, their Eq. 16):

$S_{\mathrm{qs}}=\frac{a_{0} w_{\mathrm{air}}\left[F_{\mathrm{k}}+F_{\mathrm{D}}\right]}{b_{0} \int_{0}^{\infty} r n(r) \mathrm{d} r}=\frac{a_{0} w_{\mathrm{air}}\left[F_{\mathrm{k}}+F_{\mathrm{D}}\right]}{b_{0} N_{\mathrm{cld}} r_{0} \exp \left(\sigma^{2} / 2\right)}$,

where $a_{0}$ and $b_{0}$ are variables depending on temperature and pressure (defined by Korolev and Mazin, 2003, and summarized in Appendix Table A1). A lognormal PSD was assumed to obtain the right-hand side. Korolev and Mazin (2003) argued that this steady-state approximation holds in stratocumulus clouds, except near the edges. They also stated that any averaging should be done over scales larger than $1 \mathrm{~m}$ to find supersaturation in stratocumulus clouds. This characteristic spatial scale is smaller than the considered radar volumes, allowing us to use Eq. (13). Korolev and Mazin (2003) further described a time of phase relaxation, which defines the characteristic time needed for the system to reach its quasisteady state. Away from the boundaries, this time scale is in the order of $1 \mathrm{~s}$ (not shown here), consistent with what Korolev and Mazin (2003) found. Solving for the ratio $S_{\mathrm{qs}} / w_{\text {air }}$ in Eq. (13), and substituting it into Eq. (12), the relation for the reflectivity gradient becomes

$$
\frac{\mathrm{d}(\mathrm{dBZ})}{\mathrm{d} z}=\frac{26.04 a_{0}}{b_{0} N_{\mathrm{cld}} r_{0}^{3} \exp \left(\frac{21}{2} \sigma^{2}\right)} .
$$

Using Eqs. (5) and (8), the following relation is obtained:

$$
\left[\frac{N_{\mathrm{cld}}(z)}{\left\langle N_{\mathrm{cld}}^{1 / 2}\right\rangle^{2}}\right]^{1 / 2}=\left\{\frac{208.32 a_{0} N_{\text {norm }}^{1 / 6}}{b_{0} \sqrt{Z(z)}}\left[\frac{\mathrm{d}(\mathrm{dBZ})}{\mathrm{d} z}\right]^{-1}\right\}\left\langle N_{\mathrm{cld}}^{1 / 2}\right\rangle^{-4 / 3} .
$$

On the right-hand side, all variables measured or obtained from measurements are grouped inside the braces.

Equation (15) still has two unknowns, $N_{\text {cld }}$ and $\left\langle N_{\text {cld }}^{1 / 2}\right\rangle$, but we can request that the profile of $N_{\text {cld }}$ remains close to its column-averaged value, such that we search for the value of $\left\langle N_{\text {cld }}^{1 / 2}\right\rangle$ that minimizes the following integral:

$$
\begin{aligned}
& \int_{\text {base }}^{\text {top }}\left|\sqrt{\frac{N_{\mathrm{cld}}(z)}{\left\langle N_{\mathrm{cld}}\right\rangle}}-1\right| \mathrm{d} z= \\
& \int_{\text {base }}^{\text {top }}\left|\left\{\frac{208.32 a_{0} N_{\text {norm }}^{1 / 6}}{b_{0} \sqrt{Z(z)}}\left[\frac{\mathrm{d}(\mathrm{dBZ})}{\mathrm{d} z}\right]^{-1}\right\}\left\langle N_{\text {cld }}^{1 / 2}\right\rangle^{-4 / 3}-1\right| \mathrm{d} z .
\end{aligned}
$$

Note that, as mentioned earlier, some assumptions are not valid at the cloud boundaries. Therefore, the integral here excludes these radar volumes. Moreover, volumes where the radar reflectivity is decreasing with height are also excluded, as mixing is assumed to play an important role in the microphysics there. 
Since Eq. (16) does not have an analytical solution, it needs to be solved by iterations. The right-hand side is computed using a set of values for $\left\langle N_{\text {cld }}^{1 / 2}\right\rangle$ chosen to cover the accepted climatological range for continental and maritime $N_{\text {cld }}$ (e.g., Miles et al., 2000), with a reasonably high resolution $\left(\Delta N_{\mathrm{cld}}=10 \mathrm{~cm}^{-3}\right)$. Values outside the accepted range are also considered, albeit separated by increasingly larger increments. The value of $\left\langle N_{\text {cld }}^{1 / 2}\right\rangle$ providing the minimum integral using only the good volumes in each profile is selected. However, if the minimum occurs at the edge of the considered range (i.e., no real minimum is found), no retrieval is done with the corresponding profile.

This retrieved $\left\langle N_{\text {cld }}^{1 / 2}\right\rangle$ is assumed to apply also to the rogue volumes described above, such that the remaining of the approach can still be done with them too. However, since mixing is affecting the microphysics above the level of maximum reflectivity, the column-averaged $N_{\text {cld }}$ value applied in those volumes is reduced by a factor equal to the square-root of the reflectivity ratio to its maximum value $Z(z) / Z\left(z_{\max }\right)$, close to the relation that can be deduced from the results of the field observations of Blyth and Latham (1990).

Once a value is retrieved for $\left\langle N_{\text {cld }}^{1 / 2}\right\rangle$, Eqs. (15), (8) and (5) can be rearranged to provide direct equations for the three PSD parameters, as follow:

$N_{\text {cld }}(z)=\frac{208^{2} a_{0}^{2} N_{\text {norm }}^{1 / 3}}{b_{0}^{2} Z(z)}\left[\frac{\mathrm{d}(\mathrm{dBZ})}{\mathrm{d} z}\right]^{-2}\left\langle N_{\text {cld }}^{1 / 2}\right\rangle^{-2 / 3}$

$\sigma=\sqrt{\frac{2}{9} \ln \left(\frac{\pi \rho_{\mathrm{w}}\left\langle N_{\mathrm{cld}}^{1 / 2}\right\rangle \int_{\mathrm{base}}^{\mathrm{top}} \sqrt{Z(z)} \mathrm{d} z}{6 \mathrm{LWP}}\right)}$

$r_{0}(z)=\frac{1}{2 \exp \left(3 \sigma^{2}\right)}\left[\frac{Z(z)}{N_{\mathrm{cld}}(z)}\right]^{1 / 6}$

Now with a full PSD in hand, other variables can also be computed. For instance, the supersaturation can be estimated from Eq. (13), assuming the air motion can be approximated by the radar-measured Doppler velocities (i.e., the droplets fall velocities are negligible). In addition, the effective radius at each range gate can be calculated from its definition:

$r_{\mathrm{e}}=\frac{\int_{0}^{\infty} r^{3} n(r) \mathrm{d} r}{\int_{0}^{\infty} r^{2} n(r) \mathrm{d} r}=r_{0} \exp \left(\frac{5}{2} \sigma^{2}\right)$.

Moreover, the optical depth $(\tau)$ definition states its dependence on the cloud PSD and the particles extinction crosssectional area. For spherical droplets following a lognormal PSD with a column-constant width as assumed here, $\tau$ in the visible light spectrum can be written as:

$$
\begin{aligned}
\tau & =\int_{\text {base }}^{\text {top }} \int_{0}^{\infty} 2 \pi r^{2} n(r) \mathrm{d} r \mathrm{~d} z \\
& =2 \pi \exp \left(2 \sigma^{2}\right) \int_{\text {base }}^{\text {top }} N_{\text {cld }}(z) r_{0}^{2}(z) \mathrm{d} z .
\end{aligned}
$$

The retrieved $\tau$ will be compared with the optical depth independently derived from the measurements obtained by the collocated NFOV (Chiu et al., 2006).

\section{Results}

The method described above assumes that only cloud droplets contribute to the measurements. However, marine stratocumulus clouds have a propensity to produce drizzle, and it was observed that drizzle particles are nearly always present to some degree (Kollias et al., 2011). Therefore, the method is applied here to two cases observed on Graciosa Island, in the Azores, during June 2010, when drizzle was rarely detected under the ceilometer cloud base. Moreover, the two selected periods are characterized by LWP values typically well below $100 \mathrm{~g} \mathrm{~m}^{-2}$, and by reflectivity profiles increasing with height, while staying under $-20 \mathrm{dBZ}$. It is thus believed that the drizzle contributions to the WACR measurements in those cases are minimal, and can be neglected here to demonstrate the possibilities of the new method. Its further application however requires the removal of the drizzle contribution to the measurements (Luke and Kollias, 2013).

\subsection{Case of 13 June 2010}

The first case is a stratocumulus cloud that occurred on 13 June 2010. Observed and retrieved parameters are shown for a two-hour daytime period (09:30-11:30 UTC; NFOV retrievals are available only during the day). No other cloud layer was observed during that period (e.g., cumulus or cirrus), and no significant drizzle was falling from the stratocumulus (Fig. 1a). The radar reflectivity profile peaks near the cloud top, further supporting either the lack of drizzle particles or their negligible role in the WACR moments. The Doppler measurements (Fig. 1b) show many short-lived up and down movements going through the cloud, with amplitudes typically smaller than $1 \mathrm{~m} \mathrm{~s}^{-1}$. Near the end of the twohour period, downdrafts became more dominant, and a thinning of the cloud is visible through the rising of the cloud base. Eventually the cloud dissipated in the afternoon. Overall, the cloud had a depth of 200-250 m, with a stable PWV and a smoothly varying LWP (Fig. 1c). Note that the two breaks visible in those time series are periods when the MWR was collecting measurements for calibration purpose. 

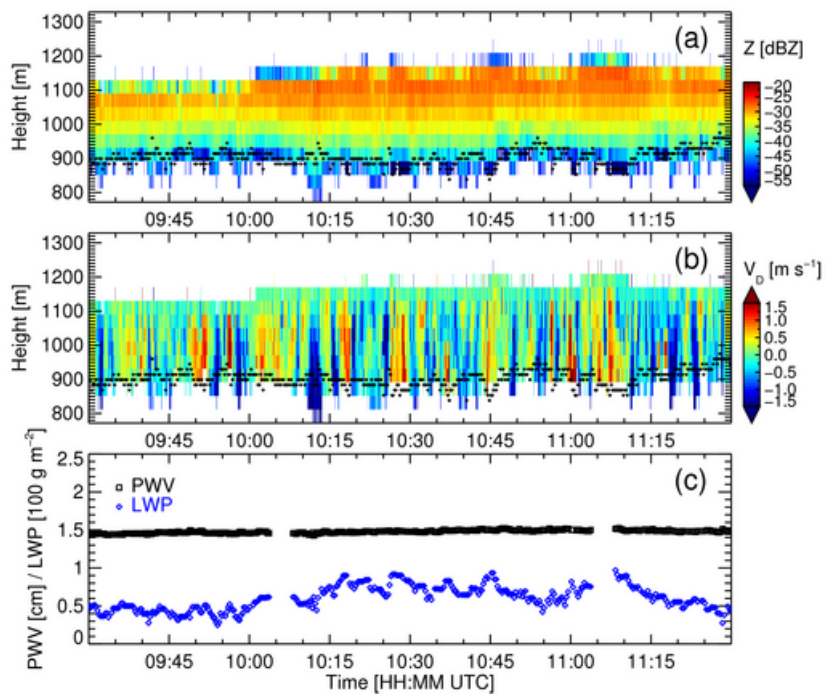

Fig. 1. Measurements made over a two-hour period on 13 June 2010: (a) radar reflectivity factor, (b) mean Doppler velocity (positive values indicate upward motion), and (c) LWP (blue) and PWV (black) from the MWR. The black dots in $(\mathbf{a}, \mathbf{b})$ represent the cloud-base height as measured by the ceilometer.

The retrieved column-averaged number concentration $\left\langle N_{\text {cld }}\right\rangle$, the height-dependent $N_{\text {cld }}$ and its standard deviation, the column-constant $\sigma$, and the height-dependent $r_{\mathrm{e}}$ and $S_{\mathrm{qs}}$ are shown in Fig. 2. Note that the "binned" aspect of $\left\langle N_{\text {cld }}\right\rangle$ visible in panel a, especially above $600 \mathrm{~cm}^{-3}$, is caused by the discrete minimization process previously described. Relatively high cloud droplet number concentrations are retrieved $\left(N_{\text {cld }}\right.$ between 400 and $\left.600 \mathrm{~cm}^{-3}\right)$ with correspondingly small effective radius ( $r_{\mathrm{e}}$ around $\left.6 \mu \mathrm{m}\right)$. Such values are typically found in continental stratocumulus clouds (Miles et al., 2000). Graciosa is an inhabited island and the air masses have origins with variable aerosol loadings (Rémillard et al., 2012). The lack of drizzle observations is consistent with the large retrieved number concentrations.

The retrieved $\sigma$ values are varying between 0.2 and 0.4 (Fig. 2c). These values are in agreement with previous data sets, as reported by Miles et al. (2000), although in the lower half of the climatological estimated range. The low retrieved values of $\sigma$ are consistent with the suggestion that the cloud droplets did not grow to drizzle sizes, keeping the PSD narrow. The supersaturation is estimated using Eq. (13). The WACR Doppler velocity measurements are assumed to represent well $w_{\text {air }}$, as no significant drizzle was detected and cloud droplets have fall velocities smaller than the radar resolution (a few $\mathrm{cm} \mathrm{s}^{-1}$ ). The resulting $S_{\mathrm{qs}}$ field has values within $0.1 \%$ (see Fig. 2e). The $S_{\mathrm{qs}}$ retrieved field seems reasonable, although very few in situ measurements are available to compare.

A sanity check was performed by computing two integrated measurements (the cloud $Z$ and LWP) using the
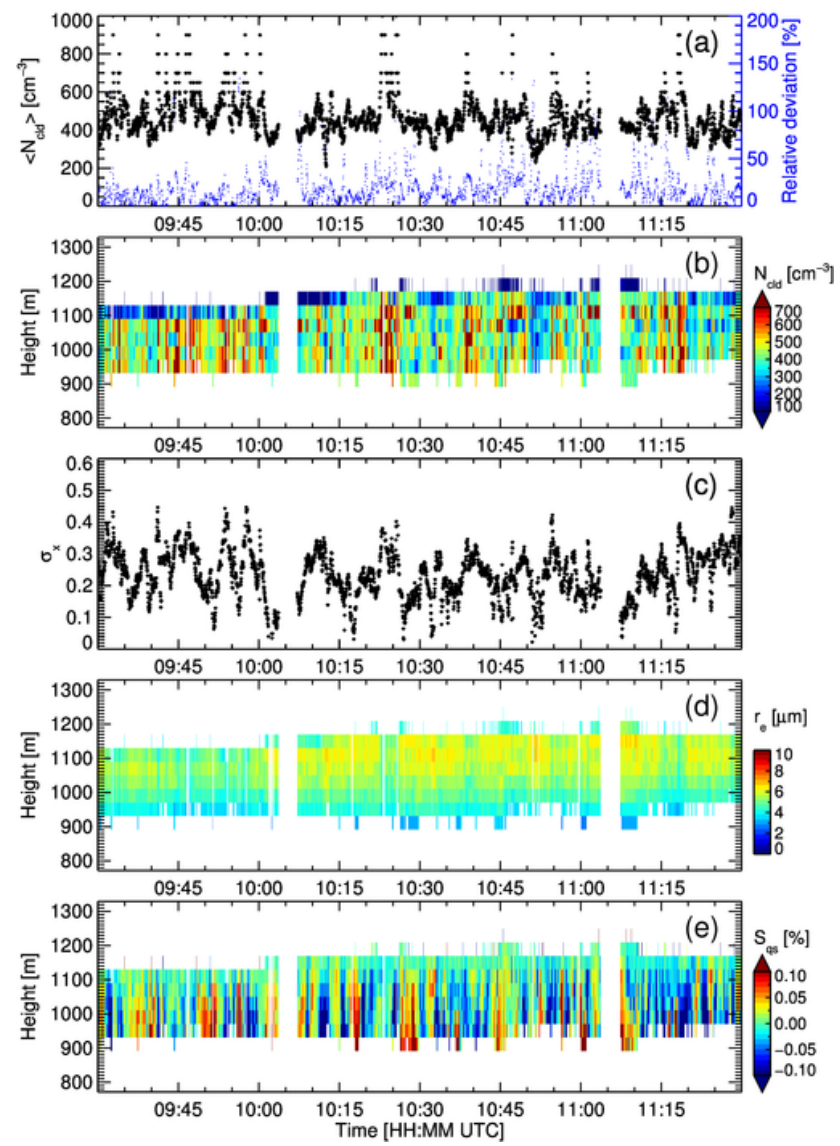

Fig. 2. Microphysical retrievals obtained over two hours on 13 June 2010: (a) column-averaged cloud droplet number concentration $\left\langle N_{\text {cld }}\right\rangle$ (deviation of each retrieved profile relative to it in blue), (b) vertical profile of cloud droplet number concentration $N_{\text {cld }}(z)$, (c) logarithmic width $\sigma$, (d) cloud effective radius profile $r_{\mathrm{e}}(z)$, and (e) supersaturation profile $S_{\mathrm{qs}}(z)$. Periods without retrievals are associated with missing MWR retrievals, or failure of reaching a minimum in Eq. (16).

retrieved PSD parameters. These values agree very well with the values measured originally by the instruments, with a slope near unity and a strong correlation coefficient (higher than 0.97; not shown here). Due to the lack of retrieval directly at the cloud base, the retrieved cloud integrated measurements are slightly biased towards values smaller than observed.

A second sanity check relates to the assumption that the number concentration of cloud droplets, although allowed to vary with height, remains close to its column-averaged value, as reported by most in situ observations. The standard deviation of the retrieved profile of $N_{\text {cld }}$ values is computed avoiding the rogue volumes described above (where $N_{\text {cld }}$ was adjusted based on the column-averaged value). The results are shown in blue in Fig. 2a, as percentage of the columnaveraged value. In general, the variability remains well below $50 \%$ of $\left\langle N_{\mathrm{cld}}\right\rangle$, frequently taking values between 10 and 
$30 \%$. Such values might seem high, given the maritime location of the observations. Nevertheless, as mentioned above, this case was likely influenced by a continental-like air mass. This kind of air mass is often characterized by more variable $N_{\text {cld }}(z)$ than marine air masses, a contrast nicely illustrated by Miles et al. (2000).

Using Eq. (19), the cloud optical depth $\tau$ is retrieved and compared with the optical depth $\tau_{\mathrm{NFOV}}$ retrieved from the NFOV measurements (Fig. 3a). The two independently retrieved optical depths agree very well, both in scales of variability and magnitude. Since the LWP variability drives to a large extent the $\tau$ variability, it is not surprising that the radar-radiometer derived and the shortwave derived optical depths agree in the observed scales of variability, as both methods use instruments equally sensitive to the LWP. Thus, the fact that the two retrievals exhibit very similar magnitudes overall $\left(\langle\tau\rangle-\left\langle\tau_{\mathrm{NFOV}}\right\rangle=-0.5\right)$ suggests that the proposed method retrieves the cloud microphysical parameters with reasonable accuracy. In particular, the slope of the relationship between cloud optical depth and LWP depends on a characteristic cloud effective radius (e.g., Kim et al., 2003). The linear regression of $\tau$ on the LWP values (Fig. 3d, e) shows very good fits, with similar slopes. Nevertheless, the spread around the fitted relation is larger for the NFOV values, indicating a stronger variability through time. This is even more visible in the time series of the retrieved cloud-top effective radius (Fig. 3b). For our retrievals, this quantity is taken as the maximum value of effective radius in each profile, while it is derived from the typical relation used in satellite studies (Eq. 1) for the NFOV, using the LWP measured by the MWR. This different variability might come from the instruments sensitivities. The radar signal is most sensitive to variations in the presence of big particles, while the effective radius is more affected by the small sizes of the PSD. Also, the assumption that $\sigma$ is constant with height might have impacted the variability of our retrievals, since the LWC and $\tau$ follow different relations with $\sigma$.

If the Frisch et al. $(1995,1998)$ radar-radiometer-based retrieval technique is applied to derive the cloud-top effective radius and the optical depth, the range of solutions is very large, depending on the assumed cloud dispersion parameter value (see the grey shaded and hatched regions in Fig. 3). Notice that our method retrieves values that are on the edge of the Frisch et al. $(1995,1998)$ retrieval range. This is explained by our retrieved values of $\sigma$ that are in the lower end of the climatological range considered in our application of the Frisch et al. $(1995,1998)$ technique.

Uncertainties on the retrievals have been evaluated by propagating an estimated error on each initial measurement: $1 \mathrm{~K}$ in the temperature field, $1 \mathrm{hPa}$ in the pressure field, $1 \mathrm{~dB}$ for the corrected reflectivity field, and around $6 \mathrm{~g} \mathrm{~m}^{-2}$ for the LWP. The first three values were chosen for illustration purpose only, although they appear reasonable and achievable. The last one however comes directly from the LWP retrieval, which in turn was derived using a physical method that can
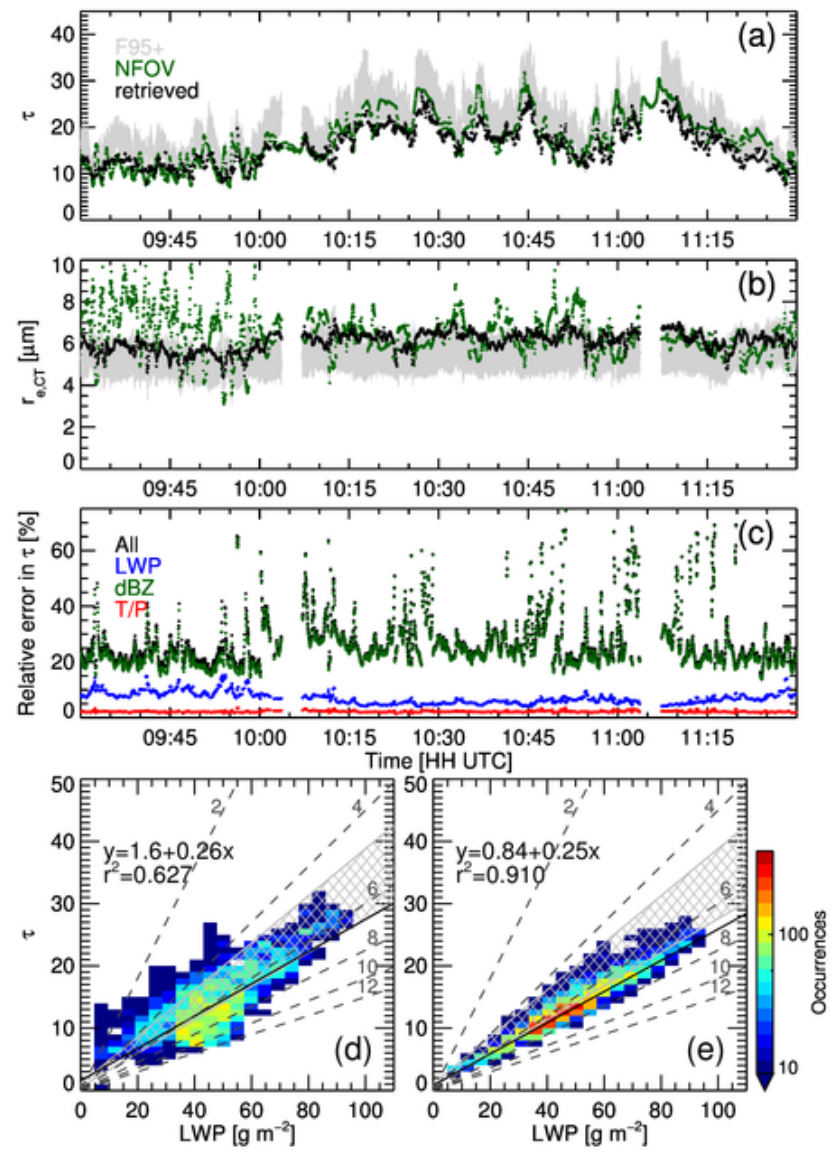

Fig. 3. Comparison results for two hours on 13 June 2010: (a) cloud optical depth $\tau$, and (b) near-cloud-top effective radius $r_{\mathrm{e}, \mathrm{CT}}$, as computed from the retrieved PSD parameters (black), and as retrieved from the NFOV and LWP measurements (green). (c) Errors in the retrieved optical depth, evaluated from the propagation of errors from each instrument and overall. The lower scatter plots show the relationship of $\tau$ as a function of the LWP values, as obtained (d) by the NFOV or (e) from the method described here. The black line represents the linear regression performed on the data (excluding those where LWP $<20 \mathrm{~g} \mathrm{~m}^{-2}$ ), with its equation and the goodness of the fit reported in the legend. The dashed lines depict the slopes expected for different values of $r_{\mathrm{e}, \mathrm{CT}}$. The grey shaded or hatched regions illustrate the range of results obtained when using the Frisch et al. $(1995,1998)$ method with $\sigma$ varied between 0.2 and 0.46 (the upper limit is the value reported by Frisch et al., 1998).

better constrain the results (Turner et al., 2007a). The uncertainty obtained from each instrument for the optical depth is shown in Fig. 3c. The main factor here is the radar reflectivity error, due to its additive character in the equations. It also results in larger uncertainties for the deeper parts of the cloud, as more radar errors get added in the column.

Overall, the uncertainty shown here is close to the range of values obtained by the Frisch et al. $(1995,1998)$ technique only by varying the lognormal width, without adding the instruments errors. It shows that the proposed method 
does constrain the retrieval parameter space. In fact, the uncertainty on the retrieved lognormal width and median radius is typically better than $20 \%$ of the retrieved value when using the errors cited above.

This comparison of the methods should be taken with caution, as the errors shown are incomplete. The only error presented above for the Frisch et al. $(1995,1998)$ technique is one originating from an assumption within the retrieval, while only instruments errors have been considered for the new technique. However, these are believed to be the main source of uncertainties for the retrieved parameters of each respective technique. The contribution of the assumptions within the new retrieval technique to the retrieval errors will be discussed in the next section.

\subsection{Case of 29 June 2010}

The second case is a stratocumulus cloud observed on the morning of 29 June 2010 (see Fig. 4) following nighttime drizzling conditions over the AMF location. Observed and retrieved parameters are shown for a two-hour daytime period (09:30-11:30 UTC). A thin cirrus layer (thickness from 0.5 to $1 \mathrm{~km}$ ) is observed after 10:00 UTC at an altitude of $10 \mathrm{~km}$. Very low intensity drizzle $(-40 \mathrm{dBZ})$ is observed sporadically below the cloud base between 10:45 and 11:15 UTC (Fig. 4a). The radar reflectivity profile peaks near the cloud top and exhibits values higher than those observed on the 13 June case. The Doppler measurements (Fig. 4b) show several coherent updraft and downdraft structures with vertical air motion magnitudes up to $1.5 \mathrm{~m} \mathrm{~s}^{-1}$. Overall, the cloud has a depth of 250-350 m, with a peak in the LWP during the thickest cloud period (Fig. 4c).

The retrieved column-averaged number concentration $\left\langle N_{\text {cld }}\right\rangle$, the height-dependent $N_{\text {cld }}$ and its standard deviation, the column constant $\sigma$, and the height-dependent $r_{\mathrm{e}}$ and $S_{\mathrm{qs}}$ are shown in Fig. 5. Lower cloud droplet number concentrations are retrieved $\left(N_{\text {cld }}\right.$ between 200 and $\left.400 \mathrm{~cm}^{-3}\right)$ with the effective radius approaching values of $10 \mu \mathrm{m}$ near the cloud top (Fig. 5a, b, d). As in the first case, the retrieved $\sigma$ values are varying between 0.2 and 0.4 (Fig. 5c) and the supersaturation $S_{\mathrm{qs}}$ field has values within $0.1 \%$ (Fig. 5e). However, it is clear in this case that more cloud area experienced higher supersaturation compared to the first case.

Note that the values obtained for $N_{\text {cld }}$ were investigated in conjunction with $w_{\text {air }}$ as estimated from the vertical velocities measured by the radar in both cases. However, only a weak positive correlation could be found, as expected from Pinsky et al. (2012) results. Also, the variability observed for $N_{\text {cld }}$ in both cases is similar to that described by Martucci and O'Dowd (2011), for which they advanced that in-cloud dynamics are at least partly responsible.

The two sanity checks described for the 13 June case were also performed for this second case. The first test results in a very similar comparison of the measured and retrieved cloudintegrated quantities. However, the second check highlights
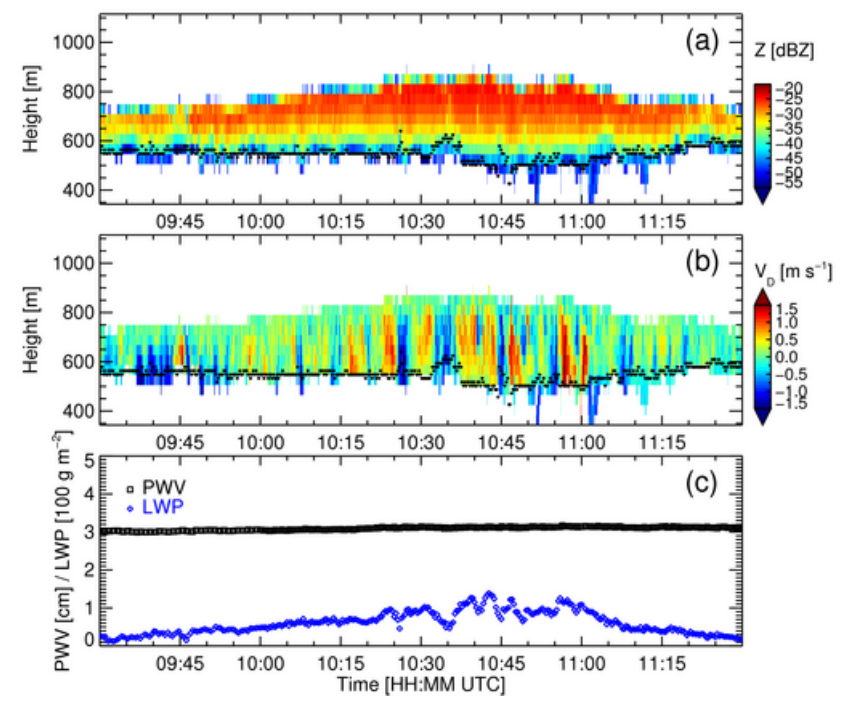

Fig. 4. Measurements made over a two-hour period on 29 June 2010: (a) radar reflectivity factor, (b) mean Doppler velocity (positive values indicate upward motion), and (c) LWP (blue) and PWV (black) from the MWR. The black dots in (a, b) represent the cloud-base height as measured by the ceilometer.

a larger relative deviation of the number concentration profiles around their averaged value. This is a simple effect of the smaller values of $N_{\text {cld }}$, while the actual deviations take similar values. Note that near-zero deviation occurs for the thinnest regions of the cloud: it denotes the small number of gates kept in the retrieval process (in some cases only one).

Once again, using Eq. (19), the cloud optical depth $\tau$ is retrieved and compared with the optical depth $\tau_{\mathrm{NFOV}}$ retrieved from the NFOV measurements (Fig. 6a). The two independently retrieved optical depths agree very well, both in scales of variability and magnitude, although the bias is higher this time $\left(\langle\tau\rangle-\left\langle\tau_{\mathrm{NFOV}}\right\rangle=-3\right)$. The presence of the cirrus layer during the observing period provides a plausible explanation for the higher NFOV optical depth values. The linear regression of $\tau$ on the LWP values (Fig. 6d, e) shows again very good fits, with similar slopes. As in the first case, the $\tau_{\mathrm{NFOV}}-$ LWP derived effective radius retrievals exhibit larger variability compared to the effective radius retrieved using the radar-radiometer method (Fig. 6b).

An estimate of the uncertainties of the retrieved optical depths is shown in Fig. 6c. The same instruments errors as the previous case are used here, except for the MWR since the more common statistical retrievals were used instead of the physical ones (see Turner et al., 2007a for more information on these). Consequently, the estimated error on the retrieved LWP is much larger (around $20 \mathrm{~g} \mathrm{~m}^{-2}$ ), and it becomes the determining factor for the thinner parts of the cloud. 

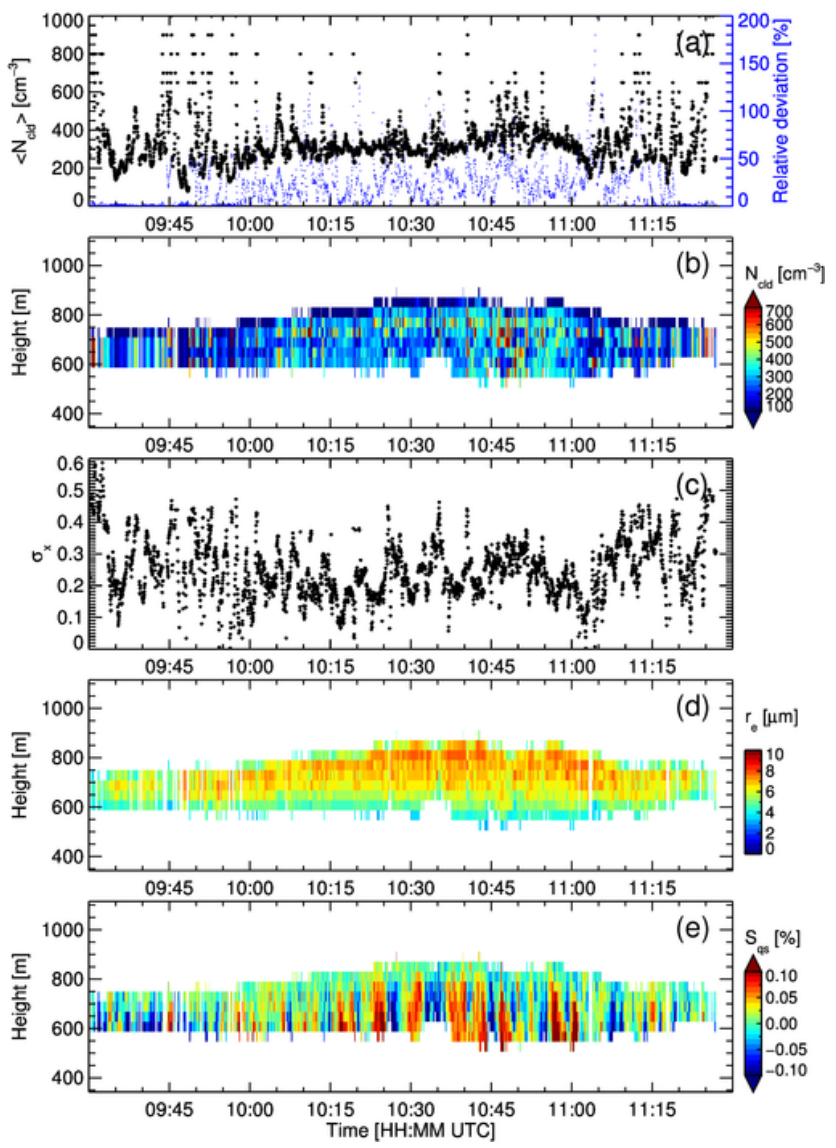

Fig. 5. Microphysical retrievals obtained over two hours on 29 June 2010: (a) column-averaged cloud droplet number concentration $\left\langle N_{\text {cld }}\right\rangle$ (deviation of each retrieved profiles relative to it in blue), (b) vertical profile of cloud droplet number concentration $N_{\text {cld }}(z)$, (c) logarithmic width $\sigma$, (d) cloud effective radius profile $r_{\mathrm{e}}(z)$, and (e) supersaturation profile $S_{\mathrm{qs}}(z)$. Periods without retrievals are associated with missing MWR retrievals, or failure of reaching a minimum in Eq. (16).

\section{Summary}

Nonprecipitating liquid phase boundary layer clouds are an important component of the earth's energy budget. Groundbased cloud radars are capable of observing their vertical structure, dynamics and boundaries (Kollias et al., 2007). However, the use of the radar observables for the retrieval of microphysical parameters is limited to the use of the radar reflectivity as the sixth moment of the cloud PSD. Empirical or theoretical relationships have been proposed to relate the radar reflectivity to the third moment of the PSD, i.e., the LWC. This is the category of radar-only-based algorithms. If LWP measurements from a microwave radiometer are available, the radar reflectivity factor can be used as a weighting function to distribute the LWP in the cloud column and thus retrieve the LWC profile with reasonable uncertainty (Frisch et al., 2000). This is the category
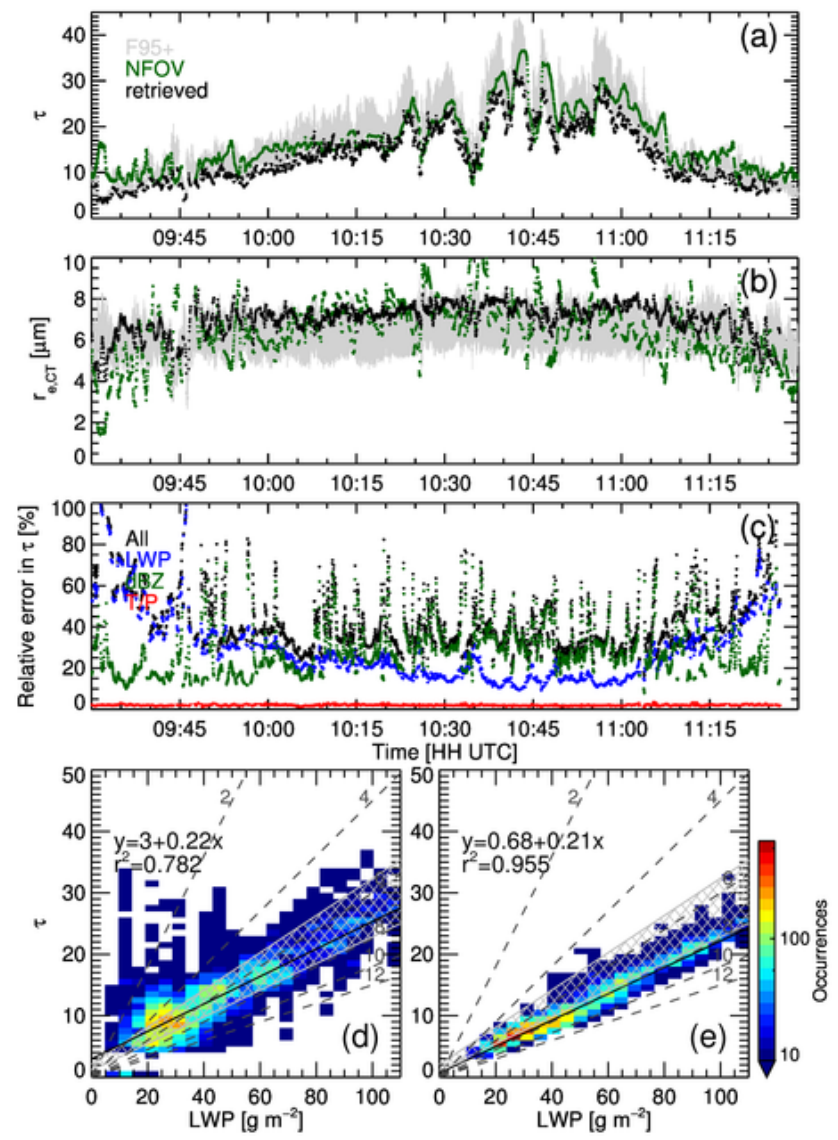

Fig. 6. Comparison results for two hours on 29 June 2010: (a) cloud optical depth $\tau$, and (b) near-cloud-top effective radius $r_{\mathrm{e}, \mathrm{CT}}$, as computed from the retrieved PSD parameters (black), and as retrieved from the NFOV and LWP measurements (green). (c) Errors in the retrieved optical depth, evaluated from the propagation of errors from each instrument and overall. The lower scatter plots show the relationship of $\tau$ as a function of the LWP values, as obtained (d) by the NFOV or (e) from the method described here. The black line represents the linear regression performed on the data (excluding those where LWP $<20 \mathrm{~g} \mathrm{~m}^{-2}$ ), with its equation and the goodness of the fit reported in the legend. The dashed lines depict the slopes expected for different values of $r_{\mathrm{e}, \mathrm{CT}}$. The grey shaded or hatched regions illustrate the range of results obtained when using the Frisch et al. $(1995,1998)$ method with $\sigma$ varied between 0.2 and 0.46 (the upper limit is the value reported by Frisch et al., 1998).

of radar-radiometer-based algorithms. Using additional constraints (e.g., number concentration and cloud dispersion parameter constant with height, or assuming a climatological value for the dispersion parameter), the cloud effective radius profile can be retrieved, and subsequently all other moments of the cloud PSD. However, these retrievals are subject to large uncertainties and generally do not agree with independent measurements of optical depth and/or solar transmission ratio (Dong et al., 1997; Mace and Sassen, 2000).

Here, a radar-radiometer-based algorithm is proposed that is a considerable modification of the Frisch et al. (1995, 
1998) work. The proposed algorithm uses additional information from the radar observables to help constrain the retrieval of cloud PSD parameters. A cloud condensational model is used to describe the profile of the radar reflectivity. It is demonstrated that the vertical gradient of the radar reflectivity combined with the steady-state supersaturation expression proposed by Korolev and Mazin (2003) can be used to constrain the relationship between cloud number concentration and dispersion parameter. Consequently, we only assume that $\sigma$ is constant with height, and we keep the cloud number concentration height dependent. However, it is required that variations of $N_{\text {cld }}$ around its column average remain small. Moreover, the mean Doppler velocity is an estimator of the vertical air motion, and it is used to estimate the cloud supersaturation using the relationship proposed by Korolev and Mazin (2003).

Observations from the recent deployment of the AMF on Graciosa Island are used to demonstrate the application of the technique in two nonprecipitating stratocumulus cloud examples. The new retrieval algorithm outputs profiles of effective radius, cloud number concentration, and supersaturation, and column values of cloud dispersion parameter. The temporal and spatial structures and magnitude of the retrieved parameters appear reasonable. However, without in situ observations, it is challenging to assess their accuracy.

Using the retrieved cloud PSD parameters, the cloud optical depth is estimated (Eq. 19) and compared to the retrieved optical depth from the NFOV radiometer (Chiu et al., 2006). In both cases, the comparison between the two optical depth estimates is very good. In the first case, the difference between the time-averaged optical depths $\left(\langle\tau\rangle-\left\langle\tau_{\mathrm{NFOV}}\right\rangle\right)$ is better than -0.5 . In the second case, the difference is greater $(-3)$, however, the presence of a thin cirrus layer could explain the higher estimates of optical depth from the NFOV radiometer. Compared to the range of solutions using the Frisch et al. $(1995,1998)$ technique, the proposed method clearly reduces the uncertainty in the estimation of the cloud effective radius and column-averaged dispersion parameter. This illustrates that, under certain conditions, the modelling of cloud and precipitation processes can help in the utilization of additional information hidden in radar observations.

An important caveat must be made though about this uncertainty comparison: the numbers presented here illustrate the possibilities of the novel technique, assuming that everything else is perfect. In fact, many assumptions were made along the way that can affect the results. For instance, the minimization process that retrieves the column-averaged number concentration has a finite resolution. Although the presence of a minimum is generally very clear, the resolution of the process affects the actual retrieved number, which in turn affects all other steps of the retrieval. Careful attention should then be given to minimize its impact, and a finer resolution than presented here should be sought.

Other assumptions made during the derivation of the method are likely to have an impact on the results
Table A1. List of symbols and selected expressions used throughout this work (adapted from Korolev and Mazin, 2003).

\begin{tabular}{|c|c|c|}
\hline Symbol & Description & Units \\
\hline$a_{0}$ & $\frac{g}{R_{\mathrm{m}} T}\left(\frac{L_{\mathrm{v}} R_{\mathrm{m}}}{c_{\mathrm{pm}} R_{\mathrm{v}} T}-1\right)$ & $\mathrm{m}^{-1}$ \\
\hline$b_{0}$ & $\frac{4 \pi \rho_{\mathrm{w}}}{\rho_{\mathrm{a}}}\left(\frac{1}{q_{\mathrm{v}}}+\frac{L_{\mathrm{v}}^{2}}{c_{\mathrm{pm}} R_{\mathrm{v}} T^{2}}\right)$ & - \\
\hline$c_{\mathrm{pm}}$ & $\begin{array}{l}\text { Specific heat capacity of moist } \\
\text { air at constant pressure }\end{array}$ & $\mathrm{Jkg}^{-1} \mathrm{~K}^{-1}$ \\
\hline$D$ & $\begin{array}{l}\text { Coefficient of water vapor } \\
\text { diffusion in the air }\end{array}$ & $\mathrm{m}^{2} \mathrm{~s}^{-1}$ \\
\hline $\mathrm{dBZ}$ & Radar reflectivity factor & $\mathrm{dBZ}$ \\
\hline$e_{\mathrm{S}}(T)$ & $\begin{array}{l}\text { Saturation vapor pressure } \\
\text { over water }\end{array}$ & $\mathrm{Pa}$ \\
\hline$F_{\mathrm{D}}$ & $\frac{\rho_{\mathrm{W}} R_{\mathrm{V}} T}{e_{\mathrm{S}}(T) D}$ & $\mathrm{~m}^{2} \mathrm{~s}^{-1}$ \\
\hline$F_{\mathrm{k}}$ & $\left(\frac{L_{\mathrm{v}}}{R_{\mathrm{V}} T}-1\right) \frac{\rho_{\mathrm{W}} L_{\mathrm{V}}}{K T}$ & $\mathrm{~m}^{2} \mathrm{~s}^{-1}$ \\
\hline$g$ & Acceleration of gravity & $\mathrm{ms}^{-2}$ \\
\hline$K$ & $\begin{array}{l}\text { Coefficient of air } \\
\text { heat conductivity }\end{array}$ & $\mathrm{J} \mathrm{m}^{-1} \mathrm{~s}^{-1} \mathrm{~K}^{-1}$ \\
\hline$L_{\mathrm{V}}$ & $\begin{array}{l}\text { Latent heat for liquid water } \\
\text { evaporation }\end{array}$ & $\mathrm{J} \mathrm{kg}^{-1}$ \\
\hline LWP & Liquid water path & $\mathrm{kg} \mathrm{m}^{-2}$ \\
\hline$N_{\text {cld }}$ & $\begin{array}{l}\text { Cloud droplet number } \\
\text { concentration }\end{array}$ & $\mathrm{m}^{-3}$ \\
\hline$N_{\text {norm }}$ & $\begin{array}{l}\text { Normalized column-averaged } \\
N_{\text {cld }}\end{array}$ & $\mathrm{m}^{-3}$ \\
\hline$n(r)$ & Cloud droplets size distribution & $m^{-4}$ \\
\hline PWV & Precipitable water vapor & $\mathrm{kg} \mathrm{m}^{-2}$ \\
\hline$Q_{\mathrm{c}}$ & Cloud liquid water content & $\mathrm{kg} \mathrm{m}^{-3}$ \\
\hline$q_{\mathrm{v}}$ & Water vapor mixing ratio & - \\
\hline$R_{\mathrm{m}}$ & $\begin{array}{l}\text { Specific gas constant of } \\
\text { moist air }\end{array}$ & $\mathrm{J} \mathrm{kg}^{-1} \mathrm{~K}^{-1}$ \\
\hline$R_{\mathrm{V}}$ & $\begin{array}{l}\text { Specific gas constant of } \\
\text { water vapor }\end{array}$ & $\mathrm{Jkg}^{-1} \mathrm{~K}^{-1}$ \\
\hline$r$ & Cloud droplet's radius & $\mu \mathrm{m}$ \\
\hline$r_{0}$ & Cloud droplet median radius & $\mu \mathrm{m}$ \\
\hline$r_{\mathrm{e}}$ & Cloud effective radius & $\mu \mathrm{m}$ \\
\hline$S$ & Degree of saturation & - \\
\hline$S_{\mathrm{qs}}$ & $\frac{a_{0} w_{\mathrm{air}}\left[F_{\mathrm{k}}+F_{\mathrm{D}}\right]}{b_{0} N_{\mathrm{cld}} r_{0} \exp \left(\sigma^{2} / 2\right)}$ & - \\
\hline$T$ & Temperature & $\mathrm{K}$ \\
\hline$t$ & Time & $\mathrm{s}$ \\
\hline$V_{\mathrm{D}}$ & Radar mean Doppler velocity & $\mathrm{ms}^{-1}$ \\
\hline$w_{\text {air }}$ & Vertical air motion & $\mathrm{ms}^{-1}$ \\
\hline$Z$ & Radar reflectivity factor & $\mathrm{mm}^{6} \mathrm{~m}^{-3}$ \\
\hline$z$ & Height coordinate & $\mathrm{m}$ \\
\hline$\rho_{\mathrm{a}}$ & Density of dry air & $\mathrm{kg} \mathrm{m}^{-3}$ \\
\hline$\rho_{\mathrm{W}}$ & Density of liquid water & $\mathrm{kg} \mathrm{m}^{-3}$ \\
\hline$\sigma$ & Lognormal width & - \\
\hline$\tau$ & Cloud optical depth & - \\
\hline
\end{tabular}


uncertainty. These include the selection of the supersaturation (Eq. 13), and the choice of taking $\sigma$ as invariant with height. However, it is challenging to fully ascertain their impact, although it is believed to be small relative to the other sources.

As in previous studies, the presence of drizzle droplets inside the cloud is an important impediment to the applicability of this novel technique. Nonetheless, it is assumed that the cloud droplets continue to grow as if no drizzle had formed, in the background. Consequently, once a separation of the cloud and drizzle contributions to the radar measurements is available (e.g., Luke and Kollias, 2013), the retrieval could be applied to virtually all stratocumulus cases. This will allow a better characterization of the possibilities of the technique, such as the range of values that can be obtained. The deployment of a new permanent ARM site in the Azores region in the near future will assist in providing even more cases, thus increasing the reliability of the results.

Continental cases are also another way of testing the technique, as their production of drizzle is usually less efficient. A few cases from the ARM site in Oklahoma were investigated, but the presence of insects there contaminates the radar signal. This contamination is as challenging to remove properly as is the drizzle signal. Different techniques exist with various degrees of success, the main one consisting in the simple removal of the volumes that appear contaminated. That is rather subjective and too radical for our purpose. Further application of the described technique is thus delayed for continental cases too, until the insect contamination can be addressed satisfactorily.

Acknowledgements. Support for this research was funded by the Office of Biological and Environmental Research, Environmental Sciences Division of the US Department of Energy as part of the Atmospheric System Research (ASR) program.

Edited by: M. Wendisch

\section{References}

Ackerman, A. S., Kirkpatrick, M. P., Stevens, D. E., and Toon, O. B.: The impact of humidity above stratiform clouds on indirect aerosol climate forcing, Nature, 432, 1014-1017, doi:10.1038/nature03174, 2004.

Ackerman, T. P. and Stokes, G. M.: The atmospheric radiation measurement program, Phys. Today, 56, 38-44, doi:10.1063/1.1554135, 2003.

Albrecht, B. A.: Aerosols, cloud microphysics, and fractional cloudiness, Science, 245, 1227-1230, doi:10.1126/science.245.4923.1227, 1989.

Atlas, D.: The estimation of cloud parameters by radar, J. Meteorol., 11, 309-317, 1954.

Blyth, A. M. and Latham, J.: Airborne studies of the altitudinal variability of the microphysical structure of small, ice-free, mon- tanan cumulus clouds, Q. J. Roy. Meteorol. Soc., 116, 14051423, doi:10.1002/qj.49711649608, 1990.

Bony, S. and Dufresne, J.-L.: Marine boundary layer clouds at the heart of tropical cloud feedback uncertainties in climate models, Geophys. Res. Lett., 32, L20806, doi:10.1029/2005GL023851, 2005.

Chiu, J. C., Marshak, A., Knyazikhin, Y., Wiscombe, W. J., Barker, H. W., Barnard, J. C., and Luo, Y.: Remote sensing of cloud properties using ground-based measurements of zenith radiance, J. Geophys. Res., 111, D16201, doi:10.1029/2005JD006843, 2006.

Dong, X., Ackerman, T. P., Clothiaux, E. E., Pilewskie, P., and Han, Y.: Microphysical and radiative properties of boundary layer stratiform clouds deduced from ground-based measurements, J. Geophys. Res., 102, 23829-23843, 1997.

Fox, N. I. and Illingworth, A. J.: The retrieval of stratocumulus cloud properties by ground-based cloud radar, J. Appl. Meteorol., 36, 485-492, 1997.

Frisch, A. S., Fairall, C. W., and Snider, J. B.: Measurement of stratus cloud and drizzle parameters in ASTEX with a Ka-band Doppler radar and a microwave radiometer, J. Atmos. Sci., 52, 2788-2799, 1995.

Frisch, A. S., Feingold, G., Fairall, C. W., Uttal, T., and Snider, J. B.: On cloud radar and microwave radiometer measurements of stratus cloud liquid water profiles, J. Geophys. Res., 103, 2319523197, 1998.

Frisch, A. S., Martner, B. E., Djalalova, I., and Poellot, M. R.: Comparison of radar/radiometer retrievals of stratus cloud liquidwater content profiles with in situ measurements by aircraft, J. Geophys. Res., 105, 15361-15364, 2000.

Frisch, S., Shupe, M., Djalalova, I., Feingold, G., and Poellot, M.: The retrieval of stratus cloud droplet effective radius with cloud radars, J. Atmos. Ocean. Tech., 19, 835-842, 2002.

Kato, S., Mace, G. G., Clothiaux, E. E., Liljegren, J. C., and Austin, R. T.: Doppler cloud radar derived drop size distributions in liquid water stratus clouds, J. Atmos. Sci., 58, 28952911, 2001.

Kim, B.-G., Schwartz, S. E., Miller, M. A., and Min, Q.: Effective radius ofcloud droplets by ground-based remote sensing: relationship to aerosol, J. Geophys. Res., 108, 4740, doi:10.1029/2003JD003721, 2003.

Kim, B.-G., Miller, M. A., Schwartz, S. E., Liu, Y., and Min, Q.: The role of adiabaticity in the aerosol first indirect effect, J. Geophys. Res., 113, D05210, doi:10.1029/2007JD008961, 2008.

Klein, S. A. and Hartmann, D. L.: The seasonal cycle of low stratiform clouds, J. Climate, 6, 1587-1606, 1993.

Kogan, Y. L., Kogan, Z. N., and Mechem, D. B.: Assessing the errors of cloud liquid water and precipitation flux retrievals in marine stratocumulus based on Doppler radar parameters, J. Hydrometeorol., 8, 665-677, doi:10.1175/JHM603.1, 2007.

Kollias, P., Clothiaux, E. E., Miller, M. A., Albrecht, B. A., Stephens, G. L., and Ackerman, T. P.: Millimeter-wavelength radars: new frontier in atmospheric cloud and precipitation research, B. Am. Meteorol. Soc., 88, 1608-1624, doi:10.1175/BAMS-88-10-1608, 2007.

Kollias, P., Rémillard, J., Luke, E., and Szyrmer, W.: Cloud radar Doppler spectra in drizzling stratiform clouds: 1. Forward modeling and remote sensing applications, J. Geophys. Res., 116, D13201, doi:10.1029/2010JD015237, 2011. 
Korolev, A. V. and Mazin, I. P.: Supersaturation of water vapor in clouds, J. Atmos. Sci., 60, 2957-2974, 2003.

Liu, Y., Geerts, B., Miller, M., Daum, P., and McGraw, R.: Threshold radar reflectivity for drizzling clouds, Geophys. Res. Lett., 35, L03807, doi:10.1029/2007GL031201, 2008.

Luke, E. and Kollias, P.: Separating cloud and drizzle radar moments during precipitation onset using Doppler spectra, J. Atmos. Ocean. Tech., doi:10.1175/JTECH-D-11-00195.1, 2013.

Mace, G. G. and Sassen, K.: A constrained algorithm for retrieval of stratocumulus cloud properties using solar radiation, microwave radiometer, and millimeter cloud radar data, J. Geophys. Res., 105, 29099-29108, 2000.

Martucci, G. and O'Dowd, C. D.: Ground-based retrieval of continental and marine warm cloud microphysics, Atmos. Meas. Tech., 4, 2749-2765, doi:10.5194/amt-4-2749-2011, 2011.

Matrosov, S. Y., Uttal, T., and Hazen, D. A.: Evaluation of radar reflectivity-based estimates of water content in stratiform marine clouds, J. Appl. Meteorol., 43, 405-419, 2004.

McComiskey, A., Feingold, G., Frisch, A. S., Turner, D. D., Miller, M. A., Chiu, J. C., Min, Q., and Ogren, J. A.: An assessment of aerosol-cloud interactions in marine stratus clouds based on surface remote sensing, J. Geophys. Res., 114, D09203, doi:10.1029/2008JD011006, 2009.

Mead, J. B. and Widener, K. B.: W-band ARM cloud radar, 32nd Int. Conf. on Radar Meteorology, Albuquerque, NM, Am. Meteorol. Soc., P1R.3, available at: http://ams.confex.com/ams/pdfpapers/ 95978.pdf (last access: 18 July 2013), 2005.

Meneghini, R.: Rain-rate estimates for an attenuating radar, Radio Sci., 13, 459-470, doi:10.1029/RS013i003p00459, 1978.

Miles, N. L., Verlinde, J., and Clothiaux, E. E.: Cloud droplet size distributions in low-level stratiform clouds, J. Atmos. Sci., 57, 295-311, 2000.

Münkel, C., Eresmaa, N., Räsänen, J., and Karppinen, A.: Retrieval of mixing height and dust concentration with lidar ceilometer, Bound.-Lay. Meteorol., 124, 117-128, doi:10.1007/s10546-0069103-3, 2007.

Pinsky, M., Khain, A., Mazin, I., and Korolev, A.: Analytical estimation of droplet concentration at cloud base, J. Geophys. Res., 117, D18211, doi:10.1029/2012JD017753, 2012.

Ramanathan, V., Cess, R. D., Harrison, E. F., Minnis, P., Barkstrom, B. R., Ahmad, E., and Hartmann, D.: Cloud-radiative forcing and climate: results from the Earth Radiation Budget Experiment, Science, 243, 57-63, 1989.
Randall, D. A., Coakley Jr., J. A., Fairall, C. W., Kropfli, R. A., and Lenschow, D. H.: Outlook for research on subtropical marine stratiform clouds, B. Am. Meteorol. Soc., 65, 1290-1301, 1984.

Rémillard, J., Kollias, P., Luke, E., and Wood, R.: Marine boundary layer cloud observations in the Azores, J. Climate, 25, 73817398, doi:10.1175/JCLI-D-11-00610.1, 2012.

Rogers, R. R. and Yau, M. K.: A Short Course in Cloud Physics, 3rd Edn., International Series in Natural Philosophy, Vol. 113, Butterworth Heinemann, Burlington, MA, 1989.

Sassen, K. and Liao, L.: Estimation of cloud content by W-band radar, J. Appl. Meteorol., 35, 932-938, 1996.

Sauvageot, H. and Omar, J.: Radar reflectivity of cumulus clouds, J. Atmos. Ocean. Tech., 4, 264-272, 1987.

Stevens, B. and Feingold, G.: Untangling aerosol effects on clouds and precipitation in a buffered system, Nature, 461, 607-613, doi:10.1038/nature08281, 2009.

Turner, D. D., Vogelmann, A. M., Austin, R. T., Barnard, J. C., Cady-Pereira, K., Chiu, J. C., Clough, S. A., Flynn, C., Khaiyer, M. M., Liljegren, J., Johnson, K., Lin, B., Long, C., Marshak, A., Matrosov, S. Y., McFarlane, S. A., Miller, M., Min, Q., Minnis, P., O'Hirok, W., Wang, Z., and Wiscombe, W.: Thin liquid water clouds: their importance and our challenge, B. Am. Meteorol. Soc., 88, 177-190, doi:10.1175/BAMS-88-2-177, 2007a.

Turner, D. D., Clough, S. A., Liljegren, J. C., Clothiaux, E. E., Cady-Pereira, K. E., and Gaustad, K. L.: Retrieving liquid water path and precipitable water vapor from the Atmospheric Radiation Measurement (ARM) microwave radiometers, IEEE T. Geosci. Remote Sens., 45, 3680-3690, doi:10.1109/TGRS.2007.903703, 2007b.

Twomey, S.: The influence of pollution on the shortwave albedo of clouds, J. Atmos. Sci., 34, 1149-1152, 1977.

Wang, J. and Geerts, B.: Identifying drizzle within marine stratus with W-band radar reflectivity, Atmos. Res., 69, 1-27, doi:10.1016/j.atmosres.2003.08.001, 2003.

Wood, R. and Hartmann, D. L.: Spatial variability of liquid water path in marine low cloud: the importance of mesoscale cellular convection, J. Climate, 19, 1748-1764, 2006. 